\title{
Xanthine Oxidase Inhibition Activity and ADMET Properties of Terap (Artocarpus odoratissimus Blanco) Leaves Metabolites: Phytochemical Screening and In Silico Studies
}

\author{
Nisa Naspiah ${ }^{1}$, Mohammad Rizki Fadhil Pratama', Sukardiman ${ }^{2, *}$
}

Nisa Naspiah', Mohammad Rizki Fadhil Pratama', Sukardiman ${ }^{2, *}$

'Doctoral Program of Pharmaceutical Sciences, Faculty of Pharmacy, Universitas Airlangga, Jl Dr Ir H Soekarno Mulyorejo, Surabaya, East Java, INDONESIA.

${ }^{2}$ Department of Pharmaceutical Sciences, Faculty of Pharmacy, Universitas Airlangga, JI Dr Ir H Soekarno Mulyorejo, Surabaya, East Java, INDONESIA.

\section{Correspondence}

\section{Sukardiman}

Department of Pharmaceutical Sciences,

Faculty of Pharmacy, Universitas Airlangga, JI Dr Ir H Soekarno Mulyorejo, Surabaya, East Java, INDONESIA.

E-mail: sukardiman@ff.unair.ac.id

History

- Submission Date: 15-04-2021;

- Review completed: 21-05-2021;

- Accepted Date: 07-06-2021.

DOI : 10.5530/pj.2021.13.148

Article Available online http://www.phcogj.com/v13/i5

\section{Copyright}

(C) 2021 Phcogi.Com. This is an openaccess article distributed under the terms of the Creative Commons Attribution 4.0 International license.

\begin{abstract}
Indonesia, with its biodiversity, is overgrown by various kinds of plants that have medicinal potential, including Terap (Artocarpus odoratissimus Blanco). The leaves of A. odoratissimus are empirically used by local people of Borneo Island to treat gout. The purpose of this study was to determine the antigout activity of the active compound from $A$. odoratissimus leaves through xanthine oxidase inhibition using the molecular docking method and to determine the ADMET properties of these compounds. Phytochemical screening showed that $A$. odoratissimus leaf extract contained alkaloids, flavonoids, steroids/triterpenoids, and phenolics. The results of TLC showed that A. odoratissimus leaf extract contained steroid and flavonoid compounds in the form of stigmasterol and rutin. The results of molecular docking showed that flavan-3-ol provided the lowest bond-free energy against xanthine oxidase with a $\Delta \mathrm{G}$ value of $-8.3 \mathrm{kcal} /$ mol, lower than allopurinol and hypoxanthine as reference ligands. Flavan-3-ol interacts with xanthine oxidase through hydrogen bonding with amino acid residues in the form of Arginine 912 and Lysine 1045 The prediction of ADMET properties from flavan-3-ol shows that the compound can be absorbed and has good permeability. Overall, the flavan-3-ol found in A. odoratissimus leaves shows the potential to be developed as a xanthine oxidase inhibitor for use in gout therapy.
\end{abstract}

Key words: Artocarpus odoratissimus, Xanthin oxidase, Molecular docking

\section{INTRODUCTION}

Indonesia is an archipelago country with extraordinary biodiversity. Various medicinal plants grow in all parts of this country. Of the total of about 40,000 types of medicinal plants that have been known to the world, 30,000 of them are alleged to be in Indonesia. This number represents $90 \%$ of the medicinal plants found in the Asia. ${ }^{1-2}$ The diversity of medicinal plants makes local people in every region in Indonesia use them to treat various types of diseases. ${ }^{3-4}$ One of the medicinal plants often used by local people in North Kalimantan is terap (Artocarpus odoratissimus Blanco). ${ }^{5}$ This plant is commonly used by local people to treat hyperuricemia or known as gout.

Gout is a disease caused by an increase in uric acid levels in the blood beyond the normal limit, which is more than $7 \mathrm{mg} / \mathrm{dL}$ for men and $5.7 \mathrm{mg} /$ $\mathrm{dL}$ for women. Symptoms of gout include pain, swelling, and redness in the joints. ${ }^{6}$ Uric acid is a weak acid produced from purine compounds, can be derived from food which is converted into hypoxanthine, then xanthine, and finally into uric acid, with the help of xanthine oxidase (XO), a hydroxylase enzyme. ${ }^{7}$ The activity of this enzyme can be inhibited by synthetic compounds such as allopurinol by forming metabolites that are more soluble than xanthine and uric acid so that they are easily excreted from the body. ${ }^{8-9}$

However, the use of synthetic compounds as gout drugs can cause some side effects, including nausea, vomiting, redness of the skin, and hair loss. ${ }^{10-12}$ Because gout therapy such as allopurinol is a long-term therapy that must be given until the therapeutic effect is achieved, the side effects are often felt by people with gout. ${ }^{13-14}$ These side effects cause inconvenience for users and cause the desire to switch to traditional medicine, including using medicinal plants. ${ }^{15}$

Some medicinal plants can be used to treat gout because they contain natural compounds in the form of secondary metabolites that can inhibit xanthine oxidase. These natural compounds include flavonoids, alkaloids, and steroids (stigmasterol and $\beta$-sitosterol). This secondary metabolite group has been isolated from several medicinal plants and has been shown to have xanthine oxidase inhibitory activity. ${ }^{16-20}$

Flavonoid compounds such as quercetin are known to interact with xanthine oxidase through in silico test. This compound interacts with xanthine oxidase through hydrogen bonds on the active site of the enzyme, namely the amino acid residues of glutamic acid 802 and threonine 1010. It is also reported that quercetin has lower free energy of binding than synthetic compounds such as allopurinol, which shows that quercetin is easier binds to xanthine oxidase compared to allopurinol. ${ }^{21}$

Artocarpus odoratissimus which is used by local people of North Kalimantan to treat gout is known to contain secondary metabolites that can act as xanthine oxidase inhibitors. Research conducted by Yen et al. ${ }^{22}$ reported that $A$. odoratissimus leaves contain stigmasterol and $\beta$-sitosterol. Other compounds such as flavonoids and steroids were also identified from A. odoratissimus leaves. Besides, flavonoid flavan-3-ol was also isolated from the methanol extract of $A$. odoratissimus leaves. ${ }^{5}$

Cite this article: Naspiah N, Pratama MRF, Sukardiman. Xanthine Oxidase Inhibition Activity and ADMET Properties of Terap (Artocarpus odoratissimus Blanco) Leaves Metabolites: Phytochemical Screening and In Silico Studies. Pharmacogn J. 2021;13(5):1150-1160. 
Plants from another genus Artocarpus, such as A. communis and A. elasticus, were identified to contain flavonoid compounds such as cyclogeracommunin and artonol A. Both of these compounds were shown to have xanthine oxidase inhibitory activity with $\mathrm{IC}_{50}$ values of $73.3 \mu \mathrm{M}$ (cyclogeracommunin) and $43.3 \mu \mathrm{M}$ (Artonol A). ${ }^{23}$ Through the ability of these compounds to inhibit xanthine oxidase, this plant of the Artocarpus genus can be used as a drug to treat gout. ${ }^{24}$ Based on this information, it is predicted that $A$. odoratissimus also has the potential to treat gout through the xanthine oxidase inhibition mechanism. Further research on the potential of $A$. odoratissimus leaves as an antigout drug through xanthine oxidase inhibition still needs to be done, given the limited scientific data that has been collected regarding the pharmacological activity and active chemical components of these plants.

Therefore, in this study, the prediction of xanthine oxidase inhibition activity through molecular docking was carried out. Molecular docking aims to determine the interaction between the active compound from $A$. odoratissimus and xanthin oxidase. This ligand and receptor interaction is carried out through computational procedures that attempt to predict the efficient non-covalent binding of macromolecules or between macromolecules (receptors) and small molecules (ligands). ${ }^{25}$ Molecular docking is an initial stage of testing before testing for antigout activity against xanthine oxidase in vitro by the active compound isolated from $A$. odoratissimus leaf extract, where the in vitro testing process and the isolation of these compounds are currently ongoing.

\section{MATERIALS AND METHODS}

\section{Instruments and materials}

The equipment used in this study includes analytical scales, maceration chamber, heating furnaces, micropipettes, $254 \mathrm{~nm}$ and $366 \mathrm{~nm}$ UV lamps, rotary evaporators, glass tools, and the ASUS Zenbook 13 UX33FA (Intel ${ }^{\circledR}$ Core (TM) i5-8265U CPU @1.6 GHz 8192 MB RAM) with Chem Bio Draw Ultra version 8.0., Chem Bio 3D Ultra version 8.0, HyperChem Professional, OpenBabel GUI, AutoDock Tools-1.5.6rc3, AutoDock Vina, and Discovery Visualizer Studio 2019.

The material studied was A. odoratissimus leaves in the form of simplicia taken from the North Kalimantan area. Besides, the materials used in this study were aquadest, aluminum foil paper, solvents (methanol, $n$-hexane, ethyl acetate, and $n$-butanol), chloroform, toluene, ammonia, Mayer's reagent, Dragendorff's reagent, Wagner's reagent, $\mathrm{FeCl}_{3}$ solution, gelatin solution, $\mathrm{HCl}, \mathrm{Mg}$ powder, $\mathrm{KOH}$, ether, anhydrous acetic acid, glacial acetic acid, $\mathrm{H}_{2} \mathrm{SO}_{4}$, and thin layer chromatography (TLC) plate.

\section{Sample preparation}

Artocarpus odoratissimus leaf samples were taken from the City of Tanjung Selor, North Kalimantan. Sample preparation was carried out by first cleaning all parts of the leaves using clean water, then drying them indirectly from the sun. Furthermore, the dried leaves are mashed to obtain simplicia powder.

\section{Extraction}

Simplicia extraction was carried out by the maceration method. The simplicia powder was macerated with ethanol for three days. Furthermore, the filtrate is filtered and concentrated using a rotary evaporator until a thick extract is obtained.

\section{PHYTOCHEMICAL SCREENING}

\section{Alkaloid Test}

The $2 \mathrm{~mL}$ extract solution was added to $2 \mathrm{~mL}$ of $2 \%$ hydrochloric acid, then added Mayer's reagent (reacts positively if a yellowish-white precipitate is formed), Dragendorff's reagent (reacts positively if it is cloudy or an orange precipitate is formed), and Wagner's reagent (reacts positively if it forms brown precipitate).

\section{Flavonoid Test}

The $2 \mathrm{~mL}$ extract solution was added with magnesium powder and 4 drops of concentrated hydrochloric acid. A positive reaction is indicated by the formation of a red, orange, or dark solution. The flavonoid test was also carried out by the TLC method using ethyl acetate eluent: formic acid : aquadest $(100: 15: 17)$ with rutin as a standard compound. After the elution process was complete, the TLC plate was sprayed with borate citrate reagent, then stains were observed under UV light 366 and $254 \mathrm{~nm}$.

\section{Phenolic Test}

The $2 \mathrm{~mL}$ extract solution was added with 3 drops of $1 \%$ ferric chloride reagent. The formation of a blue or black color indicates the presence of phenolic compounds.

\section{Saponin Test}

The 2-3 mL extract solution was put into a test tube, then $10 \mathrm{~mL}$ hot water was added and cooled. Shake vigorously for 10 seconds then add 1 drop of $2 \mathrm{~N}$ hydrochloric acid. The formation of a stable foam as high as $1-10 \mathrm{~cm}$ for not less than 10 minutes indicates the presence of phenolic compounds.

\section{Steroid/Triterpenoid Test}

The $2 \mathrm{~mL}$ extract solution was added with 10 drops of anhydrous acetic acid reagent and 2 drops of concentrated sulfuric acid. The presence of steroids is indicated by the presence of blue or green color in the solution, while triterpenoids are shown in red or purple. The steroid class test was also carried out by the TLC method using eluent $n$-hexane : ethyl acetate $(4: 1)$ and a standard compound in the form of stigmasterol. After the elution process was complete, the TLC plate was sprayed using anisaldehyde-sulfuric acid and heated. Observe the stains that form.

\section{Prediction of physicochemical and pharmacokinetic properties}

Prediction of physicochemical and pharmacokinetic properties was carried out online using SwissADME (http://www.swissadme.ch). The physicochemical and pharmacokinetic parameters observed included molecular weight, the logarithm of octanol/water partition coefficient $(\log$ P), Hydrogen Bond Acceptors (HBA), Hydrogen Bond Donors (HBD), and Topological Polar Surface Activity (TPSA), gastrointestinal (GI) absorption, blood-brain barrier (BBB) permeation, inhibition of metabolic enzymes, and skin permeation.

\section{Molecular docking}

The molecular structure of the ligands to be tested is drawn in two-dimensional form using Chem Bio Draw Ultra version 8.0. Furthermore, the three-dimensional structure of the ligand was made using Chem Bio 3D Ultra version 8.0 for energy minimization. Then do geometry optimization using HyperChem Professional, then saved in .mol format. Furthermore, the format was changed from .mol to .pdb using OpenBabel. The ligands were then prepared using AutoDock Tools-1.5.6rc3. After that, the ligands are stored in the .pdbqt format.

The receptor used was the xanthine oxidase enzyme with the PDB ID 3NRZ downloaded from the Protein Data Bank database (https://www. rcsb.org/). Protein preparation was carried out using AutoDock Tools1.5.6rc3, then saved in .pdb format. The receptor file is opened again using AutoDock Tools-1.5.6rc3 program, then saved in .pdbqt format. 
Prior to the docking process, the method that will be used is validated first. Docking was performed using AutoDock Vina from The Scripps Research Institute. The grid menu is selected to determine the tethering coordinates and grid box. The size and center of ligand docking used in site-directed docking were validated first using a complex co-crystal ligand on the crystal structure of the $3 \mathrm{NRZ}$ receptor, specifically hypoxanthine. The parameter used was the root-mean-square deviation (RMSD), with the docking results declared valid if the RMSD value of the co-crystal ligand was not more than $2.0 \AA$.

The docking process was carried out between xanthine oxidase as a receptor and a ligand for the test compound from A. odoratissimus leaves using the same parameters used in the validation process. After the docking process is complete, the resulting documents are saved for analysis.

Docking ligands were analyzed using Discovery Studio Visualizer 2019. The ligand-receptor docking model chosen was the one with the lowest free energy of binding $(\Delta \mathrm{G})$ value and the three-dimensional visualization that was closest to the receptor area. The selected ligand model was combined with the receptor using the Discovery Studio Visualizer 2019. The results of the ligand-receptor combination were analyzed for their molecular interactions in two dimensions.

\section{RESULTS}

The samples of A. odoratissimus leaf used in this analysis were collected from the City of Tanjung Selor, North Kalimantan, Indonesia. The leaves taken are old leaves and dark green in color, as seen in Figure 1. The leaves are then processed into simplicity so that the leaf samples do not rot during the storage and research period.

Simplicia A. odoratissimus leaves, which has been processed into powder, is then macerated with $96 \%$ ethanol for three days. Then, the liquid extract is concentrated using a rotary evaporator until a thick extract is obtained and is ready to be analyzed. The test to be conducted is in the form of a phytochemical screening test using multiple reagents and using the TLC method. The objective of this phytochemical screening is to classify compounds found in the therapeutic leaves, where these compounds will be tested for anti-gout activity by interacting with xanthine oxidase using the molecular docking method.

Based on the results of phytochemical screening as presented in Table 1 , it is known that $A$. odoratissimus leaves contain alkaloid, flavonoid, phenolic, and steroid/triterpenoid compounds. Meanwhile, on the results of phytochemical screening using the TLC method (Figure 2), stains appeared similar to the standard compounds used, namely rutin (flavonoids) and stigmasterol (steroids). This indicates the possibility that $A$. odoratissimus leaves contain flavonoids in the form of rutin and steroids in the form of stigmasterol.

Furthermore, the compounds tested by molecular docking were allopurinol as a reference (a synthetic anti-gout drug), hypoxanthine (a natural ligand of xanthine oxidase), beta-sitosterol and flavan-3ol (compounds isolated from A. odoratissimus leaves), pinocembrin (a class of flavonoid reported from A. odoratissimus roots), rutin (a standard compound in the test using TLC), and stigmasterol (a standard compound in the test using TLC as well as compounds isolated from

Table 1: Phytochemical screening results of $A$. odoratissimus leaf extracts.

\begin{tabular}{|cc|}
\hline Compound & Result \\
Alkaloid & + \\
Flavonoid & + \\
Phenolic & + \\
Saponin & - \\
Steroid/Triterpenoid & + \\
\hline
\end{tabular}

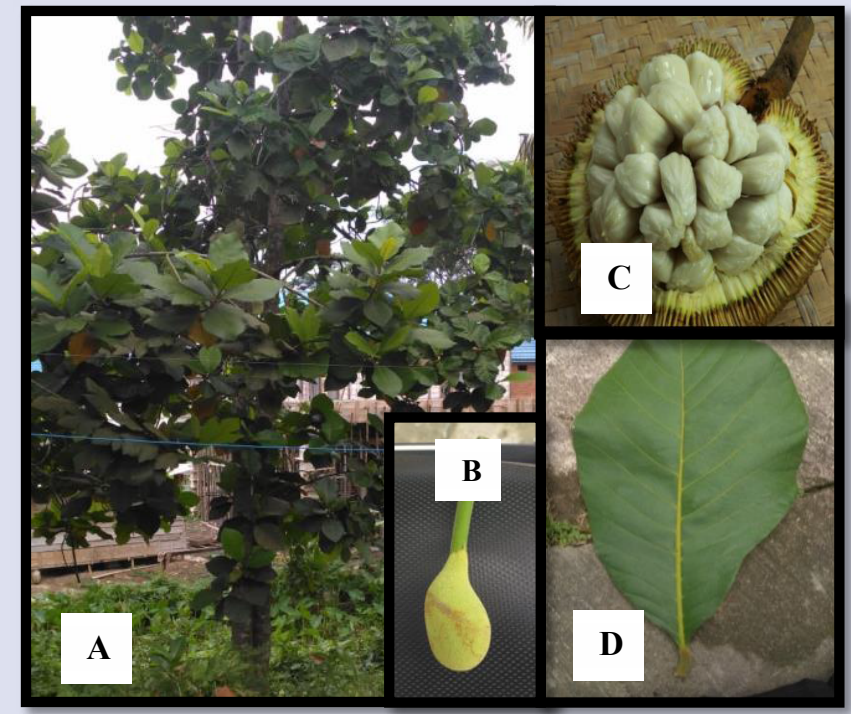

Figure 1: A. odoratissimus. A: Tree, B: Ovules, C: Fruit, D: Leaves.

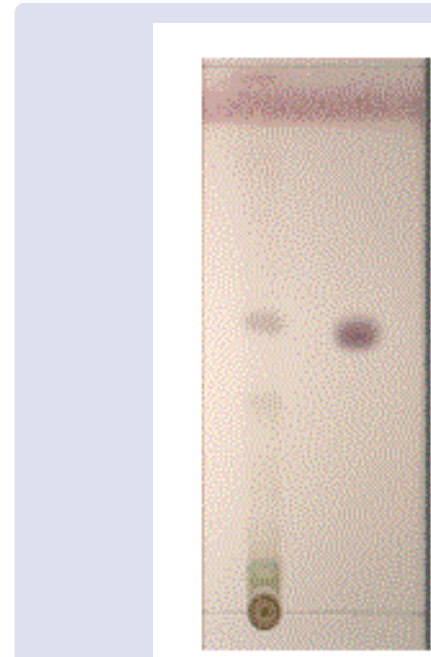

A

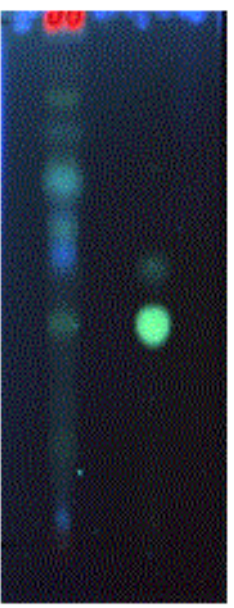

B
Figure 2: Phytochemical screening results using TLC. A: Group of steroids ( $n$-hexane: ethyl acetate (4: 1), left), Standard compound (stigmasterol, right). B: Group of flavonoids (ethyl acetate: formic acid: aquadest (100: 15: 17), left), Standard compound (rutin, right).

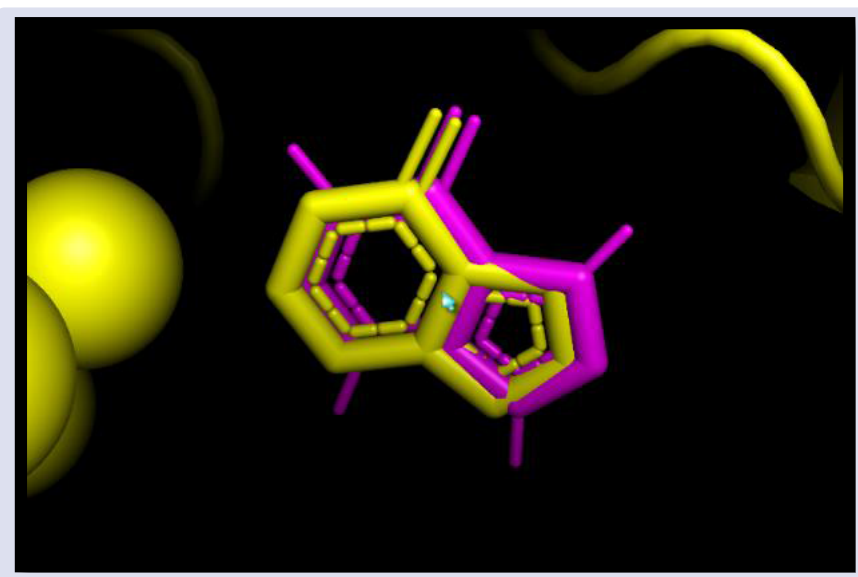

Figure 3: Visualization of docking method validation (magenta: redocking result; yellow: crystallography result). 
A. odoratissimus leaves). The structure of the compounds to be tested using molecular docking is presented in Table 2.Before molecular docking was performed, the prediction of its physicochemical and pharmacokinetic properties was carried out. The prediction results of the physicochemical properties of all tested compounds can be seen in Table 3.

The results of predictions for pharmacokinetic properties can be seen in Table 4. Furthermore, the docking process is carried out using AutoDock Vina. Before the docking process of the test compound was carried out, the docking method was validated using ligands that were bound to xanthine oxidase crystals. The co-crystal ligand used is a hypoxanthine. Method validation serves to ensure the docking method used provides valid and reliable results. The visualization of validation results can be seen in Figure 3 .

After validating, the docking process of the test ligand begins. The initial steps are the same as the preparation prior to the validation of the docking method, namely the preparation of test ligands and receptor compounds using AutoDock Tools 1.5.6rc3. After that, set the grid box according to the validation results. After the preparation process is complete, the docking process is carried out with AutoDock Vina. The docking results obtained are free energy of binding $(\Delta \mathrm{G})$ and ligandreceptor interactions. ${ }^{26}$ The results of molecular docking can be seen in Table 5. Visualization of the interaction between ligands and amino acid residues of the receptor can be seen in Figure 4-5. The amino acid residues involved in ligand and receptor interactions are different for each compound, except for hypoxanthine and allopurinol which have interactions with the same amino acid residues, particularly glutamic acid 802, arginine 880, and threonine 1010. The amino acid residues involved in hydrogen bonding with the test ligand compounds can be seen in Table 5. Based on this table, it can be seen that the flavan-3ol interacts with the xanthine oxidase through hydrogen bonds with amino acid residues in the form of arginine 912 and lysine 1045.

\section{DISCUSSION}

Based on the results of phytochemical screening as presented in Table 1 and the results of phytochemical screening using the TLC method (Figure 2), it is known that A. odoratissimus leaves contain alkaloid, flavonoid, phenolic, and steroid/triterpenoid compounds. This is in line with previous research which reported that alkaloid, flavonoid, phenolic, and steroid/triterpenoid compounds have inhibitory activity against xanthine oxidase. ${ }^{16-20}$ Based on this finding, it is predicted that

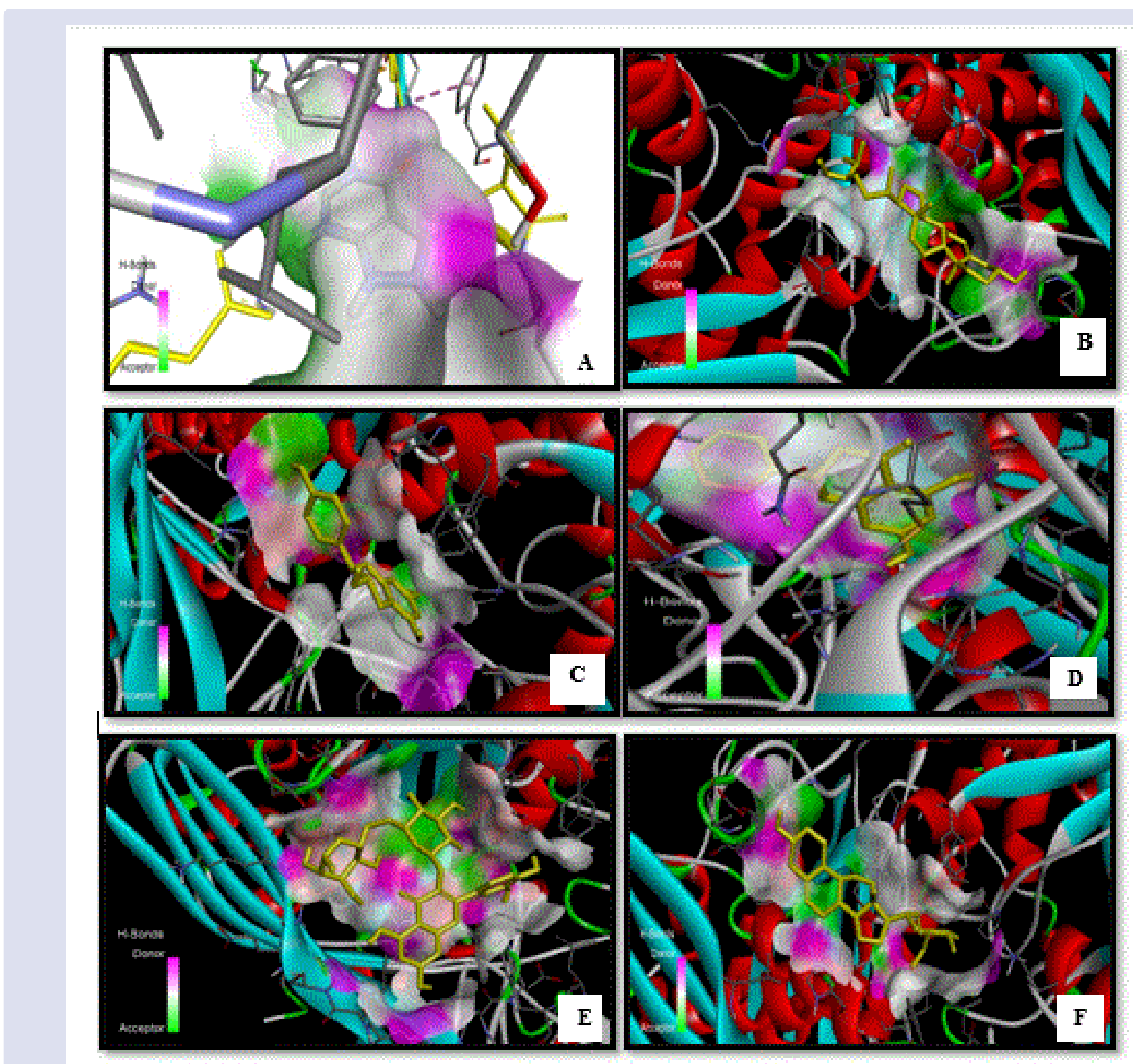

Figure 4: 3D visualization of docking Results. A: Allopurinol; B: Beta-sitosterol; C: flavan-3-ol; D: Pinocembrin; E: Rutin; F: Stigmasterol. 


\section{Table 2: Molecular structure of test compounds.}

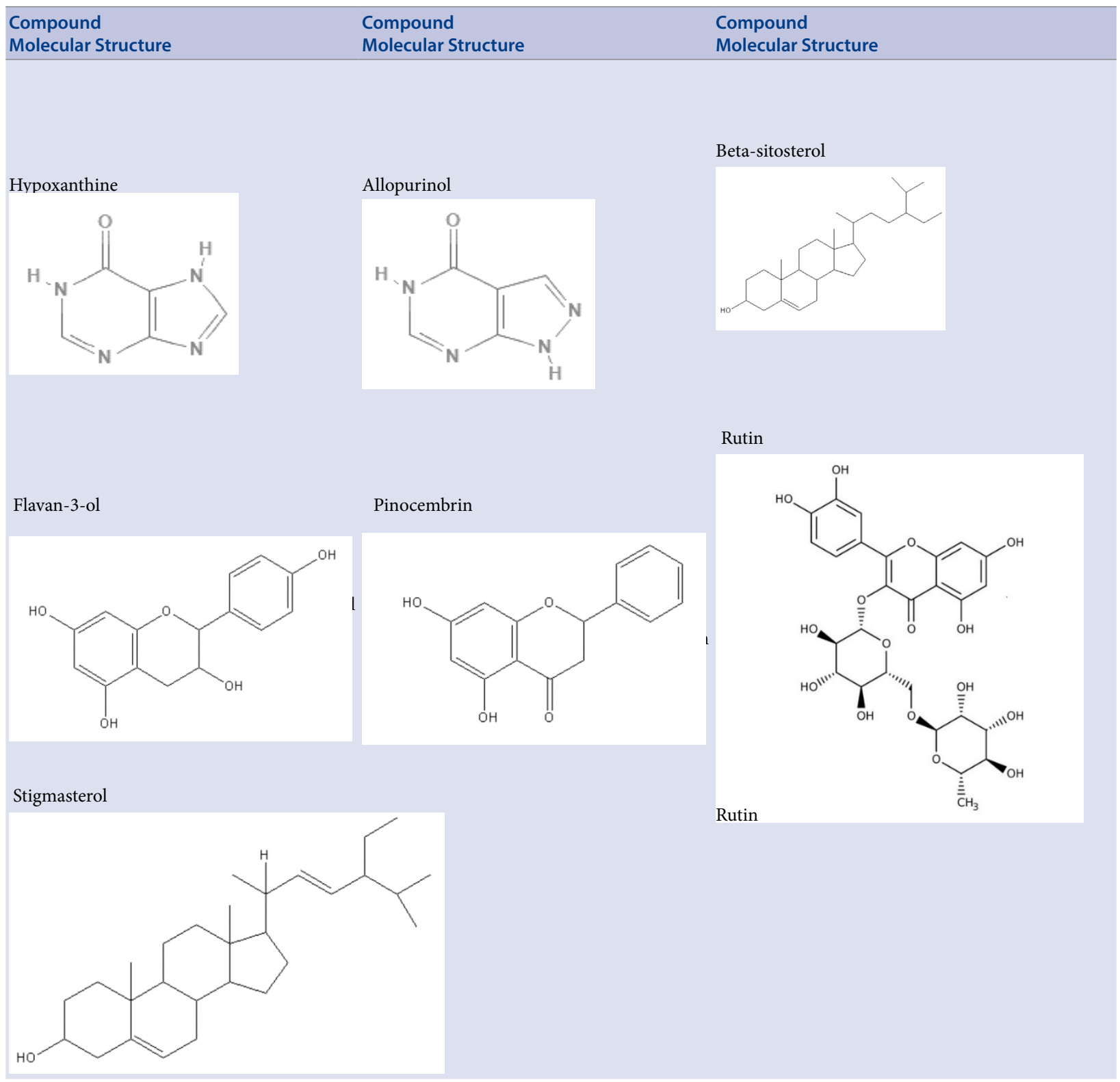

Table 3: Prediction results of the compounds physicochemical properties.

\begin{tabular}{|c|c|c|c|c|c|c|}
\hline \multirow{2}{*}{ Compounds } & \multicolumn{5}{|c|}{ Physicochemical Properties } & \multirow{2}{*}{ Lipinski Rule } \\
\hline & MW & Log-P & HBA & HBD & TPSA $\left(\AA^{2}\right)$ & \\
\hline Hypoxanthine & $136,11 \mathrm{~g} / \mathrm{mol}$ & $-1,17$ & 3 & 2 & 74,43 & Yes \\
\hline Allopurinol & $136,11 \mathrm{~g} / \mathrm{mol}$ & $-0,36$ & 3 & 2 & 74,43 & Yes \\
\hline Beta-sitosterol & $414,71 \mathrm{~g} / \mathrm{mol}$ & 6,73 & 1 & 1 & 20,23 & Yes \\
\hline Flavan-3-ol & $274,27 \mathrm{~g} / \mathrm{mol}$ & 0,79 & 5 & 4 & 90,15 & Yes \\
\hline Pinocembrin & $256,25 \mathrm{~g} / \mathrm{mol}$ & 1,27 & 4 & 2 & 66,76 & Yes \\
\hline Rutin & $610,52 \mathrm{~g} / \mathrm{mol}$ & $-3,89$ & 16 & 10 & 269,43 & No \\
\hline Stigmasterol & $412,69 \mathrm{~g} / \mathrm{mol}$ & 6,62 & 1 & 1 & 20,23 & Yes \\
\hline
\end{tabular}

$\mathrm{MW}=$ Molecular Weight; HBA = Hydrogen Bond Acceptors; HBD = Hydrogen Bond Donor; TPSA = Topological Polar Surface Active 

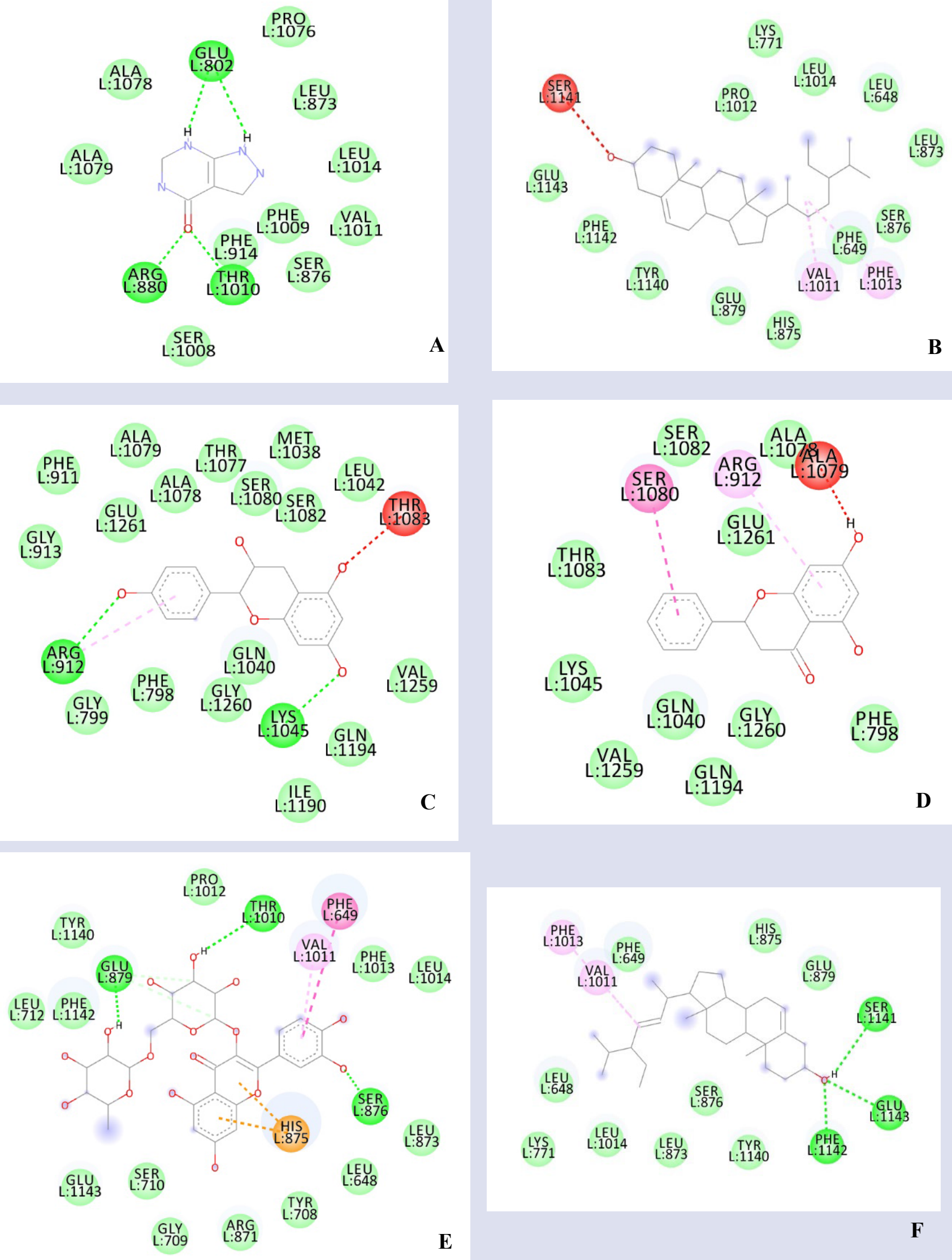

Figure 5: 2D visualization of docking results. A: Allopurinol; B: Beta-sitosterol; C: flavan-3-ol; D: Pinocembrin; E: Rutin; F: Stigmasterol. 
Table 4: Predicted results of the compounds pharmacokinetic properties.

\begin{tabular}{|c|c|c|c|c|}
\hline \multirow[b]{2}{*}{ Compounds } & \multicolumn{4}{|c|}{ Pharmacokinetic Parameters } \\
\hline & Gl Absorption & BBB Permeation & $\begin{array}{l}\text { P450 Cytochrome Enzyme } \\
\text { Inhibitors }\end{array}$ & Skin Permeation $(\mathrm{cm} / \mathrm{s})$ \\
\hline Hypoxanthine & High & No & No & $-7,48 \mathrm{~cm} / \mathrm{s}$ \\
\hline Allopurinol & High & No & No & $-7,61 \mathrm{~cm} / \mathrm{s}$ \\
\hline Beta-sitosterol & Low & No & No & $-2,20 \mathrm{~cm} / \mathrm{s}$ \\
\hline Flavan-3-ol & High & No & No & $-7,46 \mathrm{~cm} / \mathrm{s}$ \\
\hline Pinocembrin & High & Yes & $\begin{array}{ll}\cdot & \text { CYP1A2 Inhibitors } \\
\cdot & \text { CYP2C19 Inhibitors }\end{array}$ & $-5,82 \mathrm{~cm} / \mathrm{s}$ \\
\hline Rutin & Low & No & No & $-10,26 \mathrm{~cm} / \mathrm{s}$ \\
\hline Stigmasterol & Low & No & CYP2C9 Inhibitors & $-2,74 \mathrm{~cm} / \mathrm{s}$ \\
\hline
\end{tabular}

Table 5: Molecular docking results.

\begin{tabular}{|c|c|c|c|}
\hline Compounds & $\begin{array}{l}\text { Free energy of binding } / \Delta \mathrm{G} \\
(\mathrm{kcal} / \mathrm{mol})\end{array}$ & Interaction Type & Amino Acid Residues Involved \\
\hline Hypoxanthine & -6.3 & Hydrogen Bond & GLU L:802, ARG L:880, THR L:1010 \\
\hline Allopurinol & -6.4 & Hydrogen Bond & GLU L:802, ARG L:880, THR L:1010 \\
\hline Beta-sitosterol & -6.9 & Van der Waals interactions & $\begin{array}{l}\text { PRO L:1012, LYS L:771, GLU L:1143, PHE L:1142, TYR } \\
\text { L:1140, GLU L:879, HIS L:875, SER L:876, PHE L:1013 }\end{array}$ \\
\hline Flavan-3-ol & -8.3 & Hydrogen Bond & ARG L:912, LYS L:1045 \\
\hline Pinocembrin & -8.9 & Van der wails interactions & $\begin{array}{l}\text { THR L:1083, LYS L:1045, VAL L:1259, GLN L:1040, } \\
\text { GLY L:1260, GLN L:1194, PHE L:798, GLU L:1261, ALA } \\
\text { L:1078, SER L:1082 }\end{array}$ \\
\hline Rutin & -7.1 & Hydrogen Bond & THR L:1010, GLU L:879, SER L:876 \\
\hline Stigmasterol & -7.2 & Hydrogen Bond & SER L:1141, GLU L:1143, PHE L:1142 \\
\hline
\end{tabular}

A. odoratissimus leaves have antigout activity by inhibiting xanthine oxidase by the compounds identified in A. odoratissimus leaves.

Before molecular docking was performed, the prediction of its physicochemical and pharmacokinetic properties was carried out. The results (Table 3) show that beta-sitosterol, rutin, and stigmasterol do not meet Lipinski's rules of five. Lipinski's rules of five are the rules used to predict the absorption and permeability of a drug compound so that the drug is good for use in the body. According to Lipinski's rules of five, a compound has good absorption and permeability in the body, if it has a molecular weight of less than 500 , the number of donor hydrogen bonds is $\leq 5$, the number of acceptor hydrogen bonds is $\leq 10$, and the $C \log \mathrm{P}$ value $\leq 5$ or $\mathrm{MLogP}$ value $<4.15$. A compound is declared to meet Lipinski's rules of five if it meets the four conditions or at least meets three conditions. Based on this, it is known that all test compounds except rutin have good absorption and permeability in the body. ${ }^{27}$

The results of predictions for pharmacokinetic properties can be seen in Table 4. These results indicate that rutin, stigmasterol, and betasitosterol have a low or less absorption capacity when compared to others. This is because the MLogP value is more than 4.15 for the betasitosterol and stigmasterol compounds, where the MLogP value more than 4.15 indicates poor absorption, according to Lipinski's rules of five. This $\log \mathrm{P}$ value is the partition coefficient value between n-octanol and water, which represents the lipophilic (lipid-soluble) properties of a compound. The higher the $\log \mathrm{P}$ value, the more lipophilic properties of the compound, or else, the compound is more non-polar. ${ }^{28}$ If a compound is too non-polar, it can cause the compound to bind very tightly to the lipid membrane and make it difficult to get to the receptor. This is because, before binding to the receptor, the drug compound must pass through polar body fluids. The highly lipophilic compounds are difficult to pass through these body fluids. ${ }^{29}$ Therefore, the polarity of a drug compound has certain limitations, as regulated in Lipinski's rules of five, so that the drug can be well absorbed, distributed to the site of action, and interacts with the target receptor to cause the desired activity.

Furthermore, based on the predicted results of pharmacokinetic properties, the only compound that can cross the blood-brain barrier is pinocembrin. This allows pinocembrin to be distributed into the brain. The ease of penetrating the blood-brain barrier can have a positive effect, if the compound has pharmacological effects on the brain, and it can also have a negative effect, if the compound does not have a pharmacological effect on the brain, but causes side effects or toxic effects on the brain. ${ }^{30}$

The next pharmacokinetic property is the ability to influence metabolism through inhibition of cytochrome P450 enzymes that are involved in many metabolic processes. ${ }^{31}$ Based on the prediction results obtained, it is known that pinocembrin compounds can inhibit the action of the cytochrome P1A2 (CYP1A2) and cytochrome P2C19 (CYP2C19) enzymes, and stigmasterol compounds can inhibit cytochrome P2C9 (CYP29). This shows that pinocembrin and stigmasterol can influence metabolic processes that involve these cytochrome enzymes.

Then, for skin permeation as indicated by the Log Kp value, the prediction results show that only beta-sitosterol compounds have a log Kp value $>-2.5$. Hardjono ${ }^{32}$ stated that compounds that have low skin permeability have a $\log \mathrm{Kp}$ value $>-2.5$. Therefore, from the results of the prediction of skin permeability, it can be seen that the compound which may have low skin permeability is beta-sitosterol.

After knowing the physicochemical and pharmacokinetic properties of the test compound, molecular docking was carried out on several test compounds, with the comparison compound being allopurinol. Allopurinol is a type of synthetic drug that is currently commonly used to treat gout. This drug is a hypoxanthine analog, which works by inhibiting the formation of uric acid through xanthine oxidase inhibition. ${ }^{33}$

The ligand and receptor molecules are first prepared before docking is conducted. The geometry optimization is carried out to reduce the steric energy of the ligands so that the structure is more stable and the docking process is more optimal. ${ }^{34}$ After that, the ligand and receptor molecules are given hydrogen atoms and charges according to the amount of charge contained in each constituent atom. Then adjust the size and coordinates of the grid box and save it in the config file in the ".txt" format. The dimensions of the grid box used in the docking method validation are 40 x 40 x $40 \AA$. 
Furthermore, the docking process is carried out using AutoDock Vina. Before the docking process of the test compound was carried out, the docking method was validated using ligands that were bound to xanthine oxidase crystals. The co-crystal ligand used is a hypoxanthine. Method validation serves to ensure the docking method used provides valid and reliable results. This can be seen from the parameter in the form of the Root Mean Square Deviation (RMSD) value. ${ }^{35}$ The RMSD value is a measurement of two poses by comparing the atomic positions between the experimental structure and the predicted structure. A method is declared valid if it has an RMSD value $<2.0 \AA . .^{36}$ If the RMSD value meets the requirements, then the docking method is suitable for use for molecular docking of the compounds to be tested. The RMSD value from the docking validation was $0.379 \AA$. This value indicates that the docking method used is valid and can be used for docking the test compound with xanthine oxidase receptors. The visualization of validation results can be seen in Figure 3.

After validating, the docking process of the test ligand begins. The results of molecular docking can be seen in Table 5. The smaller the $\Delta \mathrm{G}$ value, the better the interaction between the ligand and the receptor (Du et al., 2016). The docking results showed that the pinocembrin test compound had the smallest $\Delta \mathrm{G}$ value. However, when viewed from its effect on metabolism, this compound still needs to be considered. Another compound with comparable $\Delta \mathrm{G}$ value but quite good pharmacokinetic properties are flavan-3-ol, which has been isolated from A. odoratissimus leaves. This compound is ideal for use as medicine, both in terms of pharmacokinetics and pharmacology when viewed from its interaction with xanthine oxidase. All the tests and natural ligands have different bond areas with xanthine oxidase.

When compared between the test ligand which has the smallest $\Delta \mathrm{G}$ value with reference ligands (allopurinol) and co-crystal ligands (hypoxanthine), flavan-3-ol interacts much better with xanthine oxidase. This shows that this compound has the potential as an antigout which has a better interaction with xanthine oxidase than allopurinol.

\section{CONCLUSION}

Based on the tests, it can be concluded that the test compound with xanthine oxidase inhibitory activity is better than allopurinol both in terms of interaction with xanthine oxidase and pharmacokinetic is flavan-3-ol. Another compound that also has a good interaction with xanthine oxidase is pinocembrin. However, this compound is less than ideal in terms of pharmacokinetics by affecting metabolism. Flavan3-ol and pinocembrin are predicted to be present in the leaves of $A$. odoratissimus. Both of these compounds have good potential to be developed into anti-gout drugs. The in vitro anti-gout activity test of these two compounds is still needed to be done to confirm their activity as xanthine oxidase inhibitors.

\section{ACKNOWLEDGMENTS}

Authors would like to thank the Doctoral Program Research Funding, Directorate General of Research and Development Strengthening, Ministry of Education and Culture of Republic of Indonesia (DRPM) for the 2020 fiscal year for the funding provided.

\section{REFERENCES}

1. Arozal W, Louisa M, Soetikno V. Selected Indonesian Medicinal Plants for the Management of Metabolic Syndrome: Molecular Basis and Recent Studies. Front Cardiovasc Med 2020;7:82. https://dx.doi. org/10.3389/fcvm.2020.00082

2. Romulo A, Zuhud EAM, Rondevaldova J, Kokoska L. Screening of in vitro antimicrobial activity of plants used in traditional Indonesian medicine. Pharm Biol 2018;56(1):287-93. https://doi.org/10.1080/138 80209.2018.1462834
3. Jadid N, Kurniawan E, Himayani CES, Andriyani, Prasetyowati I, Purwani $\mathrm{Kl}$, et al. An ethnobotanical study of medicinal plants used by the Tengger tribe in Ngadisari village, Indonesia. PLoS One 2020;15(7):e0235886. https://dx.doi.org/10.1371/journal. pone. 0235886

4. Roosita K, Kusharto CM, Sekiyama M, Fachrurozi Y, Ohtsuka R Medicinal plants used by the villagers of a Sundanese community in West Java, Indonesia. J Ethnopharmacol 2008;115(1):72-81. https:// doi.org/10.1016/j.jep.2007.09.010

5. Tasmin N, Erwin, Kusuma IW. Isolasi, identifikasi dan uji toksisitas senyawa flavonoid fraksi kloroform dari daun terap (Artocarpus odoratissimus Blanco). J Kim Mulawarman 2014;12(1):45-53.

6. Ragab G, Elshahaly M, Bardin T. Gout: An old disease in new perspective - A review. J Adv Res 2017;8(5):495-511. https://dx.doi. org/10.1016/j.jare.2017.04.008

7. Maiuolo J, Oppedisano F, Gratteri S, Muscoli C, Mollace V. Regulation of uric acid metabolism and excretion. Int J Cardiol 2016;213:8-14. https://doi.org/10.1016/j.ijcard.2015.08.109

8. Chen C, Lü JM, Yao O. Hyperuricemia-Related Diseases and Xanthine Oxidoreductase (XOR) Inhibitors: An Overview. Med Sc Monit 2016;22:2501-12. https://doi.org/10.12659/msm.899852

9. Pacher P, Nivorozhkin A, Szabó C. Therapeutic effects of xanthine oxidase inhibitors: renaissance half a century after the discovery of allopurinol. Pharmacol Rev 2006;58(1):87-114. https://doi. org/10.1124/pr.58.1.6

10. Jordan A, Gresser U. Side Effects and Interactions of the Xanthine Oxidase Inhibitor Febuxostat. Pharmaceuticals 2018;11(2):51. https:// doi.org/10.3390/ph11020051

11. Sharma G, Govil DC. Allopurinol induced erythroderma. Indian J Pharmacol 2013:45(6):627-8. https://doi.org/10.4103/02537613.121381

12. Yaylacı S, Demir MV, Temiz T, Tamer A, Uslan MI. Allopurinolinduced DRESS syndrome. Indian J Pharmacol 2012;44(3):412-4. https://dx.doi.org/10.4103/0253-7613.96351

13. Claus LW, Saseen JJ. Patient considerations in the management of gout and role of combination treatment with lesinurad. Patient Relat Outcome Meas 2018;9:231-8. https://doi.org/10.2147/prom.s108868

14. Finch $A$, Kubler $P$. The management of gout. Aust Prescr 2016;39(4):119-22. https://dx.doi.org/10.18773/austprescr.2016.047

15. Hao S, Zhang C, Song H. Natural Products Improving Hyperuricemia with Hepatorenal Dual Effects. Evid Based Complement Alternat Med 2016;2016:7390504. https://doi.org/10.1155/2016/7390504

16. Fachriyah E, Ghifari MA, Anam K. Isolation, Identification, and Xanthine Oxidase Inhibition Activity of Alkaloid Compound from Peperomia pellucida. IOP Conf Ser Mater Sci Eng 2017;349:012017. https://doi.org/10.1088/1757-899X/349/1/012017

17. Duong NT, Vinh PD, Thuong PT, Hoai NT, Thanh LN, Bach TT, et al. Xanthine oxidase inhibitors from Archidendron clypearia (Jack.) I.C. Nielsen: Results from systematic screening of Vietnamese medicinal plants. Asian Pac J Trop Med 2017;10(6):549-56. https:// doi.org/10.1016/j.apjtm.2017.06.002

18. Ferraz-Filha ZS, Araújo MCdPM, Ferrari FC, Dutra IPAR, SaúdeGuimarães DA. Tabebuia roseoalba: In Vivo Hypouricemic and Antiinflammatory Effects of Its Ethanolic Extract and Constituents. Planta Med 2016;82(16):1395-402. https://doi.org/10.1055/s-0042-105878

19. Chen CY, Huang CC, Tsai KC, Huang WJ, Huang WC, Hsu YC, et al. Evaluation of the Antihyperuricemic Activity of Phytochemicals from Davallia formosana by Enzyme Assay and Hyperuricemic Mice Model. Evid Based Complement Alternat Med 2014;2014:873607. https://doi.org/10.1155/2014/873607 
20. de Souza MR, de Paula CA, de Resende MLP, Grabe-Guimarães A, Filho JDdS, Saúde-Guimarães DA. Pharmacological basis for use of Lychnophora trichocarpha in gouty arthritis: anti-hyperuricemic and anti-inflammatory effects of its extract, fraction and constituents. J Ethnopharmacol 2012;142(3):845-50. https://doi.org/10.1016/j. jep.2012.06.012

21. Hendriani R, Nursamsiar N, Tjitraresmi A. In vitro and in silico evaluation of xanthine oxidase inhibitory activity of quercetin contained in Sonchus arvensis leaf extract. Asian J Pharm Clin Res 2017;10(14):50-3. https://doi.org/10.22159/ajpcr.2017.v10s2.19486

22. Yen KH, Nyok N, Kutoi CJ, Hamzah AS, Lim IF. Chemical Constituents of Artocarpus odoratissimus from Sarawak. J App Pharm Sci 2017;7(8):137-41. http://dx.doi.org/10.7324/JAPS.2017.70819

23. Lin KW, Liu CH, Tu HY, Ko HH, Wei BL. Antioxidant prenylflavonoids from Artocarpus communis and Artocarpus elasticus. Food Chem 2009;115(2):558-62. https://doi.org/10.1016/j.foodchem.2008.12.059

24. Sharma A, Gupta P, Verma AK. Preliminary nutritional and biological potential of Artocarpus heterophyllus L. shell powder. J Food Sci Technol 2015;52(3):1339-49. https://doi.org/10.1007/s13197-013$1130-8$

25. Trott O, Olson AJ. AutoDock Vina: improving the speed and accuracy of docking with a new scoring function, efficient optimization, and multithreading. J Comput Chem 2010;31(2):455-61. https://doi. org/10.1002/jcc.21334

26. Forli S, Huey R, Pique ME, Sanner MF, Goodsell DS, Olson AJ. Computational protein-ligand docking and virtual drug screening with the AutoDock suite. Nat Protoc 2016;11:905-19. https://doi. org/10.1038/nprot.2016.051

27. Lipinski CA, Lombardo F, Dominy BW, Feeney PJ. Experimental and computational approaches to estimate solubility and permeability in drug discovery and development settings. Adv Drug Deliv Rev 2001;46(1-3):3-26. https://doi.org/10.1016/s0169$409 \times(00) 00129-0$
28. Utomo SB, Sanubari F, Utami B, Nurhayati ND. Analysis of a Quantitative Relationship Between the Structure and Analgesic Activity of Meperidin Derivatives Using Semi-Empirical AM1 Method. JKPK J Kim Pendidik Kim 2017;2(3):158-68. https://doi.org/10.20961/ jkpk.v2i3.12092

29. Pajouhesh H, Lenz GR. Medicinal chemical properties of successful central nervous system drugs. NeuroRx 2005;2(4):541-53. https:// doi.org/10.1602/neurorx.2.4.541

30. Bors LA, Erdő F. Overcoming the Blood-Brain Barrier. Challenges and Tricks for CNS Drug Delivery. Sci Pharm 2019;87(1):6. https://doi. org/10.3390/scipharm87010006

31. Palleria C, Di Paolo A, Giofrè C, Caglioti C, Leuzzi G, Siniscalchi A et al. Pharmacokinetic drug-drug interaction and their implication in clinical management. J Res Med Sci 2013;18(7):601-10.

32. Hardjono S. Prediksi Sifat Farmakokinetik, Toksisitas dan Aktivitas Sitotoksik Turunan N-Benzoil-N'-(4-fluorofenil)tiourea sebagai Calon Obat Antikanker melalui Pemodelan Molekul. J Ilmu Kefarmasian Indones 2016;14(2):246-55.

33. Ritter J, Flower R, Henderson G, Loke YK, MacEwan D, Rang $H$. Rang \& Dale's Pharmacology. 9 ${ }^{\text {th }}$ ed. Amsterdam: Elsevier; 2019.

34. Meng XY, Zhang HX, Mezei M, Cui M. Molecular docking: a powerful approach for structure-based drug discovery. Curr Comput Aided Drug Des 2011;7(2):146-57. https://doi.org/10.2174/157340911795677602

35. Castro-Alvarez A, Costa AM, Vilarrasa J. The Performance of Several Docking Programs at Reproducing Protein-Macrolide-Like Crystal Structures. Molecules 2017;22(1):136. https://doi.org/10.3390/ molecules22010136

36. Ramírez D, Caballero J. Is It Reliable to Take the Molecular Docking Top Scoring Position as the Best Solution without Considering Available Structural Data? Molecules 2018;23(5):1038. https://doi. org/10.3390/molecules23051038

37. Du X, Li Y, Xia YL, Ai SM, Liang J, Sang $P$, et al. Insights into ProteinLigand Interactions: Mechanisms, Models, and Methods. Int J Mol Sci 2016;17(2):144. https://doi.org/10.3390/ijms17020144 


\section{GRAPHICAL ABSTRACT}

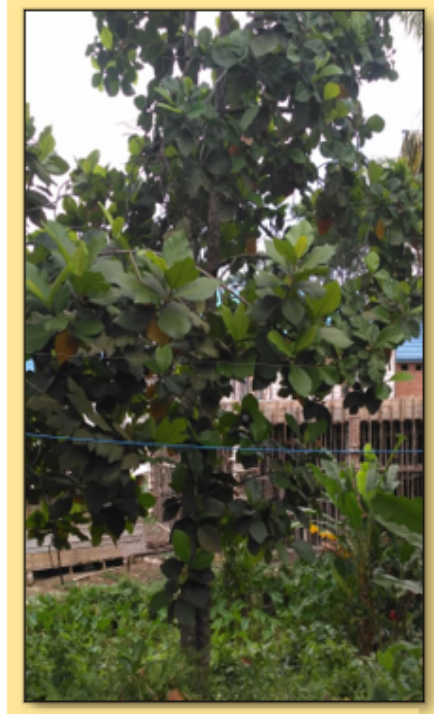

Artocarpus odoratissimus

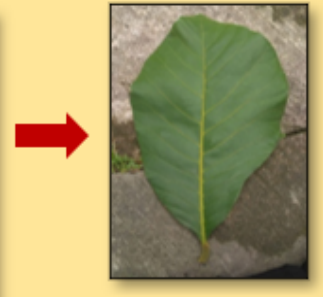

A. odoratissimus Leaf

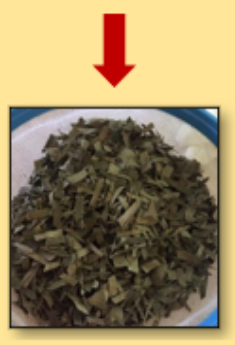

Simplisia of A. odoratissimus Leaf
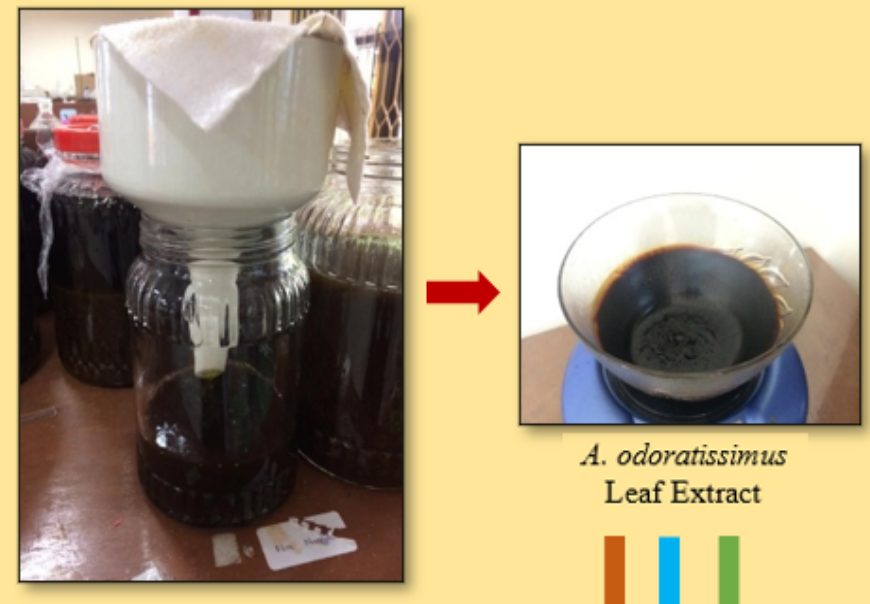

A. odoratissimus Leaf Extract

Maceration Method

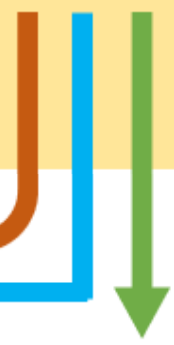

\section{Molecular Docking}

\begin{tabular}{|l|c|}
\hline \multicolumn{1}{|c|}{ Compound } & Result \\
\hline Alkaloid & $\sqrt{ }$ \\
\hline Flavonoid & $\sqrt{ }$ \\
\hline Phenolic & $\sqrt{ }$ \\
\hline Saponin & $\times$ \\
\hline Steroid/Triterpenoid & $\sqrt{ }$ \\
\hline
\end{tabular}

Steroid Test

Flavonoid Test

\section{Phytochemical Screening}

\section{Physicochemical and Pharmacokinetic Properties}

\begin{tabular}{|l|c|c|c|c|c|c|}
\hline \multirow{2}{*}{ Compounds } & \multicolumn{5}{|c|}{ Physicochemical Properties } & \multirow{2}{*}{$\begin{array}{c}\text { Lipinski } \\
\text { Rule }\end{array}$} \\
\cline { 2 - 6 } & $\begin{array}{c}\text { MW } \\
(\mathrm{g} / \mathrm{mol})\end{array}$ & $\begin{array}{c}\text { Log- } \\
\mathbf{P}\end{array}$ & HBA & HBD & $\begin{array}{c}\text { TPSA } \\
\left(\AA^{2}\right)\end{array}$ & Yes \\
\hline Hypoxanthine & 136,11 & $-1,17$ & 3 & 2 & 74,43 & Yes \\
\hline Allopurinol & 136,11 & $-0,36$ & 3 & 2 & 74,43 & Yes \\
\hline Beta-sitosterol & 414,71 & 6,73 & 1 & 1 & 20,23 & Yes \\
\hline Flavan-3-ol & 274,27 & 0,79 & 5 & 4 & 90,15 & Yes \\
\hline Pinocembrin & 256,25 & 1,27 & 4 & 2 & 66,76 & Yes \\
\hline Rutin & 610,52 & $-3,89$ & 16 & 10 & 269,43 & No \\
\hline Stigmasterol & 412,69 & 6,62 & 1 & 1 & 20,23 & Yes \\
\hline
\end{tabular}

\begin{tabular}{|l|c|c|l|c|}
\hline \multirow{3}{*}{ Compounds } & \multicolumn{4}{|c|}{ Pharmacokinetic Parameters } \\
\cline { 2 - 5 } & $\begin{array}{c}G I \\
\text { Absorption }\end{array}$ & $\begin{array}{c}\text { BBB } \\
\text { Permeation }\end{array}$ & $\begin{array}{c}\text { P450 Cytochrome } \\
\text { Enzyme Inhibitors }\end{array}$ & $\begin{array}{c}\text { Skin Permeation } \\
(\mathbf{c m} / \mathbf{s})\end{array}$ \\
\hline Hypoxanthine & High & No & No & $-7,48$ \\
\hline Allopurinol & High & No & No & $-7,61$ \\
\hline Beta-sitosterol & Low & No & No & $-2,20$ \\
\hline Flavan-3-ol & High & No & No & $-7,46$ \\
\hline Pinocembrin & High & Yes & $\begin{array}{l}\text { CYP1A2 } \\
\text { Inhibitors } \\
\text { CYP2C19 } \\
\text { Inhibitors }\end{array}$ & $-5,82$ \\
\hline Rutin & Low & No & No & $-10,26$ \\
\hline Stigmasterol & Low & No & CYP2C9 Inhibitors & $-2,74$ \\
\hline
\end{tabular}

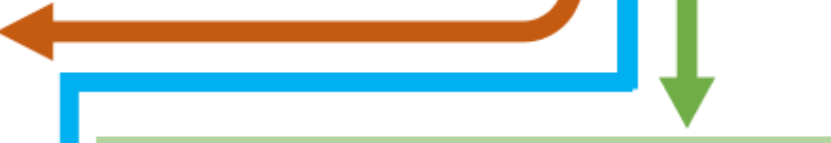

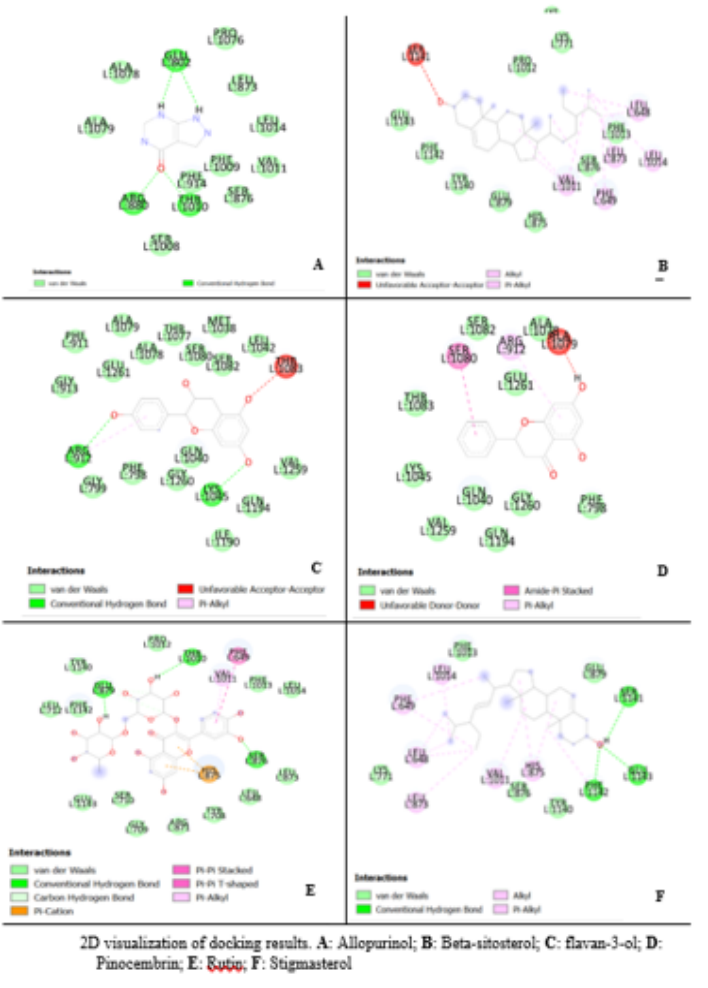




\section{ABOUT AUTHORS}

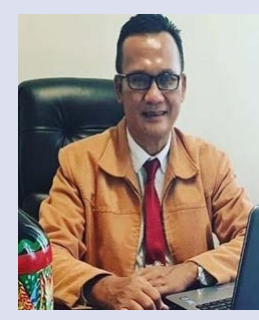

Sukardiman is Professor Pharmacognosy in Department of Pharmaceutical sciences, Faculty of Pharmacy at Airlangga University, Surabaya, Indonesia. He has fast experience in the area of Pharmacognosy, Natural Product and Pharmacology. He has projects in developing Product Antidiabetic, Anticancer from Indonesian Herbal Medicine, and Herbal Standardization. Guiding students for PhD, studies of various Universities. He has publication in National and International Journal.

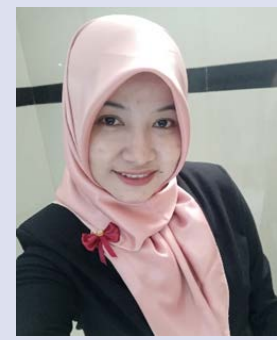

Nisa Naspiah is a Doctoral Student on Faculty of Pharmacy at Airlangga University, Surabaya, as well as lecturer in Department of Pharmaceutical biology, Faculty of Pharmacy, Mulawarman University, Samarinda, Indonesia. She has experience in research related to medical herbs, such as the pharmacological activity of a medicinal plant from various regions in Borneo, Indonesia. Her current research was investigate the antigout activity of Artocarpus odoratissimus Blanco leaves through various methods, namely in silico and in vitro.

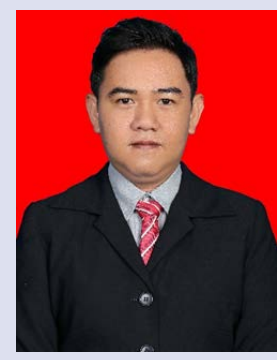

Mohammad Rizki Fadhil Pratama is a Doctoral Student on Faculty of Pharmacy at Airlangga University, Surabaya, as well as Assistant Professor of Medicinal Chemistry at Universitas Muhammadiyah Palangkaraya, Palangka Raya, Indonesia. He has extensive experience in research with in silico methods, especially molecular docking, and ADMET studies. His current research project includes the design and synthesis of isolated compounds from Boesenbergia pandurata as anti-breast cancer. He is also Editor-in-Chief of the Borneo Journal of Pharmacy.

Cite this article: Naspiah N, Pratama MRF, Sukardiman. Xanthine Oxidase Inhibition Activity and ADMET Properties of Terap (Artocarpus odoratissimus Blanco) Leaves Metabolites: Phytochemical Screening and In Silico Studies. Pharmacogn J. 2021;13(5):1150-1160. 